\title{
DESAIN ANTARMUKA BERORIENTASI BUDAYA
}

\author{
Restyandito $^{(1)}$ \\ dito@ukdw.ac.id
}

\begin{abstract}
Abstraksi
Perkembangan teknologi yang demikian pesat, mengakibatkan semakin banyak orang yang menggunakannya dalam berbagai aspek kehidupan mereka. Penetrasi teknologi yang mengglobal tersebut diperhadapkan pada latar belakang budaya pengguna yang berbagai macam. Hal tersebut mengakibatkan banyak pengguna yang mengalami kesulitan ketika berusaha memahami antarmuka piranti yang digunakan. Makalah ini merupakan penelitian studi pustaka yang dilakukan penulis, untuk mengetahui faktor apa saja yang berpengaruh dalam perancangan antarmuka pengguna. Salah satu kunci keberhasilan perancangan antarmuka yang baik, adalah dengan memahami dan mempertimbangkan dimensi budaya seperti yang telah dikemukakan oleh Hall dan Hofstede.
\end{abstract}

Kata Kunci : Interaksi Manusia Komputer, dimensi budaya, kulturabilitas , hofstede , pemetaan antarmuka

\section{Latar Belakang}

Penetrasi teknologi akibat perkembangan teknologi yang demikian pesat telah meliputi hampir semua aspek kehidupan manusia. Hal ini telah diprediksi oleh Gordon E. More dalam hukum yang terkenal disebut Moore's Law, yang menyatakan bahwa kemampuan komputasi komputer akan meningkat dua kali lipat setiap tahunnya. Pada kenyataanya kita dapat melihat bahwa perkembangan teknologi bukan hanya meningkat dua kali lipat tetapi lebih besar dari itu. Hal ini di dukung dengan industri masal yang menyebabkan semakin murahnya berbagai piranti teknologi komputer. Oleh sebab itu, tidak mengherankan jika banyak masyarakat yang beberapa tahun lalu belum mengenal teknologi, sekarang telah menggunakan teknologi dalam kehidupan sehari-hari mereka. Teknologi yang dimaksud di sini adalah teknologi informasi dan komunikasi yang saat ini sering tidak dapat dipisahkan dari kehidupan manusia akibat konvergensi berbagai periferal teknologi.

\footnotetext{
${ }^{1}$ Teknik Informatika, Fakultas Teknologi Informasi,Universitas Kristen Duta Wacana
} 
Krisnawati dan Restyandito (2008) menunjukkan bahwa pengguna di daerah berkembang seperti Indonesia, mengalami lompatan teknologi, yang mengakibatkan masalah dalam penggunaan teknologi tersebut, dalam hal ini, Krisnawati dan Restyandito, menyoroti penggunakan telepon genggam. Kurangnya pengalaman menggunakan komputer maupun berkomunikasi menggunakan telepon kabel, merupakan faktor utama pengguna mengalami kesulitan dalam memahami icon-icon yang digunakan yang kebanyakan mengadaptasi metafor meja kerja pada komputer.

Selain hal tersebut, penulis beranggapan bahwa latar belakang budaya juga memiliki peranan dalam berhasil atau tidaknya pengguna memahami interface suatu piranti digital. Makalah ini merupakan hasil penelitian pustaka yang mencoba merumuskan pengaruh budaya terhadap perancangan antarmuka komputer.

\section{Desain Antar Muka dan Budaya}

Gould (2005), mengemukakan bahwa nilai-nilai budaya dan komunikasi timbul akibat proses persepsi manusia. Nilai-nilai tersebut digunakan untuk memahami hal-hal yang terjadi di sekitar manusia. Sebagai contoh, pemahaman terhadap arti suatu warna, sering dipengaruhi oleh latar belakang pengguna.Warna putih bagi sebagian orang dianggap sebagai warna yang menggambarkan kepolosan dan kesucian, bagi orang lain dianggap sebagai representasi dari kematian dan kedukaan. Desain antarmuka yang tidak memperhatikan latar belakang budaya penggunanya, dapat menimbulkan permasalahan dalam menerjemahkan suatu simbol antarmuka. Teknologi yang banyak digunakan masyarakat pada saat ini, merupakan teknologi yang dihasilkan dari negara maju dengan memperhatikan budaya mereka sesuai dengan kebutuhan dan kebiasaan di sana. Jika teknologi tersebut diadaptasi secara langsung bagi pengguna dari negara berkembang seperti Indonesia, maka tidak mengherankan jika banyak pengguna yang mengalami kesulitan. Gambar 1-3 menunjukkan perbedaan layout situs berita BBC yang memperhatikan cara orientasi membaca orang yang menggunakannya.

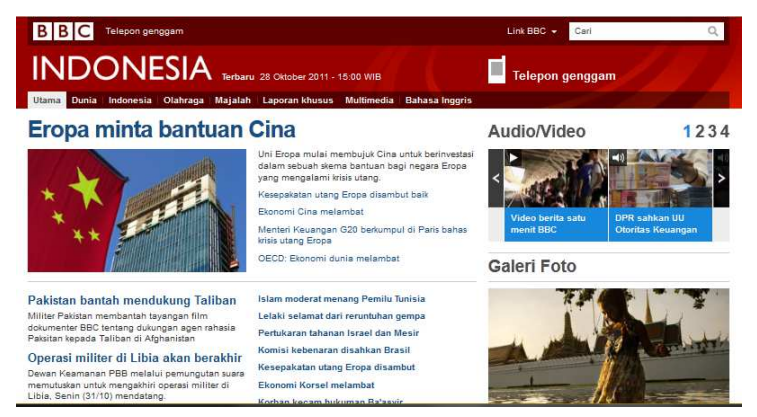

Gambar 1. Situs BBC berbahasa Indonesia (http://www.bbc.co.uk/indonesia) 


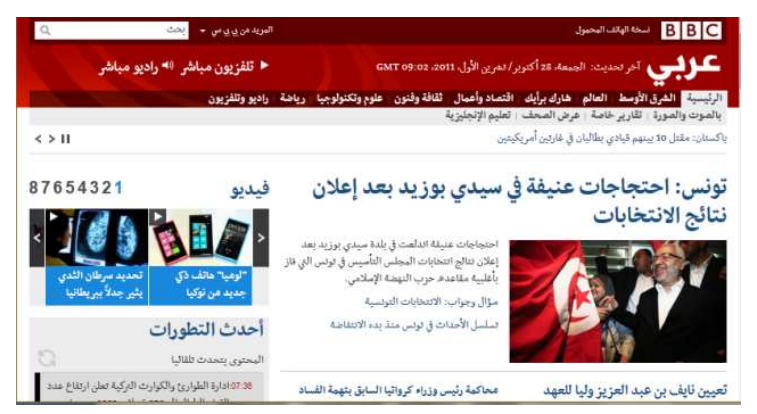

Gambar 2. Situs BBC berbahasa Arab (http://www.bbc.co.uk/arabic)

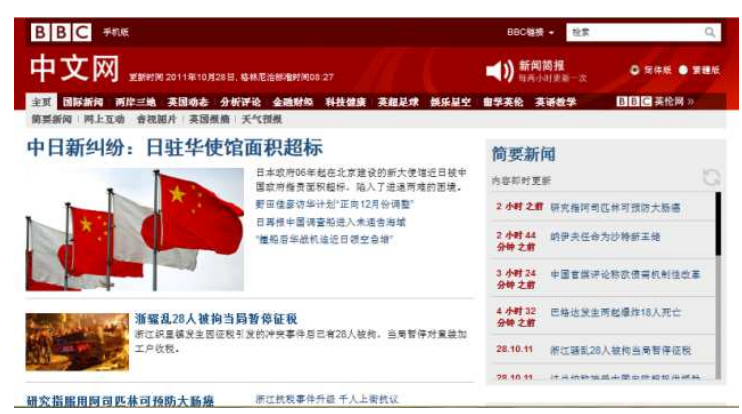

Gambar 3. Situs BBC berbahasa Cina

(http://www.bbc.co.uk/chinese)

Culturability merupakan istilah yang dibuat oleh Barber dan Badre (1998) untuk menekankan pentingnya hubungan antara budaya (culture) dan daya guna (usability), implikasinya, sesuatu yang "user friendly" (mudah digunakan) untuk sebagian orang dengan budaya tertentu, mungkin dianggap susah dan membingungkan bagi orang dengan latar belakang budaya yang lain.

Sebagai contoh, perbedaan format penulisan tanggal, dimana orang Indonesia menggunakan format DD/MM/YYYY sementara orang Amerika menggunakan format MM/DD/YYYY. Bagi pengguna yang tinggal di Indonesia, mungkin tidak menyadari kesalahan yang terjadi pada saat memasukkan tanggal 10 November 2011, dimana antarmuka yang digunakan adalah format Amerika, sehingga yang tersimpan di komputer adalah 11 Oktober 2011.

Contoh yang lain adalah penggunaan simbol dan icon, seperti tampak pada Gambar 4 berikut: 


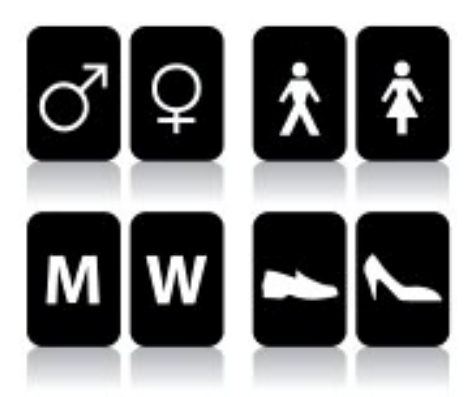

\section{Gambar 4. Berbagai simbol kamar kecil.}

(http://us.cdn1.123rf.com/168nwm/emirsimsek/emirsimsek1001/emirsimsek100100209/6180087vector-collection-of-restroom-signs.jpg)

Jika seseorang melihat salah satu simbol di atas di suatu pertokoan, kemungkinan besar mereka dapat menafsirkan arti yang berbeda. Seseorang yang tinggal di Perancis, mungkin akan menafsirkan lambang huruf $M$ sebagai tanda petunjuk ke arah Metro (kendaraan umum setempat), demikian pula orang Indonesia yang melihat lambang sepatu, mungkin akan mengartikannya sebagai penunjuk jalan ke toko sepatu, padahal kedua lambang tersebut menunjukkan kamar kecil untuk pria.

\section{Dimensi Budaya}

Kamus Besar Bahasa Indonesia mende-finisikan budaya sebagai pikiran, hasil akal budi atau sesuatu yang sudah menjadi kebiasaan. Sedangkan kebudayaan dijelaskan sebagai keseluruhan pengetahuan manusia sbg makhluk sosial yg digunakan untuk memahami lingkungan serta pengalamannya dan yang menjadi pedoman tingkah lakunya. Biasanya istilah tersebut digunakan untuk menjelaskan sekelompok orang yang memiliki beberapa aspek yang sama dalam kehidupan mereka. Perbedaan nilai-nilai budaya yang terdapat diantara kelompok orang tersebut akan membentuk bagaimana sikap dan perilaku masyarakat dalam kelompok tertentu.

Hal (1976) menekankan bahwa bahasa non-verbal memegang peranan penting dalam komunikasi interkultural. Hal memperkenalkan konsep yang disebut chronemics, proxemics dan context dalam teori komunikasi interkultural, seperti diringkas dalam tabel 1 berikut:

Tabel 1. Constructs for Intercultural Communication

\begin{tabular}{|l|l|l|}
\hline \multicolumn{2}{|c|}{ CHRONEMICS } \\
\hline \multicolumn{2}{|c|}{$\begin{array}{c}\text { Construct of Intercultural } \\
\text { Communication Theory }\end{array}$} & Description \\
\hline Subjective & Technical & Physical context of experience over \\
\hline
\end{tabular}




\begin{tabular}{|c|c|c|}
\hline \multirow{3}{*}{$\begin{array}{l}\text { Division of } \\
\text { Time }\end{array}$} & & time \\
\hline & Formal & $\begin{array}{l}\text { Conventional system of } \\
\text { measurement of time }\end{array}$ \\
\hline & Informal & $\begin{array}{l}\text { Perception of rate at which time } \\
\text { passes }\end{array}$ \\
\hline \multirow{2}{*}{$\begin{array}{l}\text { Connection of } \\
\text { Time and } \\
\text { Activity }\end{array}$} & Monochronic & Perform one activity at a time \\
\hline & Polychronic & $\begin{array}{l}\text { Perform more than one activity at a } \\
\text { time }\end{array}$ \\
\hline \multicolumn{3}{|c|}{ PROXEMICS } \\
\hline \multicolumn{2}{|c|}{ Technical } & Physical constraint of space \\
\hline \multicolumn{2}{|c|}{ Formal } & Architecture \\
\hline \multicolumn{2}{|c|}{ Informal } & $\begin{array}{l}\text { Informal Patterns of proximity and } \\
\text { arrangement that determine group } \\
\text { orientation }\end{array}$ \\
\hline \multicolumn{3}{|c|}{ CONTEXT } \\
\hline \multicolumn{2}{|c|}{ High Context } & $\begin{array}{l}\text { Information must be explicitly } \\
\text { stated in the text of the message }\end{array}$ \\
\hline \multicolumn{2}{|c|}{ Low Context } & $\begin{array}{l}\text { Social system shapes meaning } \\
\text { through non-verbal behavior, actual } \\
\text { text is secondary }\end{array}$ \\
\hline
\end{tabular}

Pemahaman terhadap pembagian waktu, secara formal, antara budaya berbeda. Sebagian budaya menghitung hari berdasarkan rotasi matahari, sementara budaya lain memperhitungkan rotasi bulan. Secara informal, makna "sebentar" juga berbeda, bagi orang yang tinggal di kota besar, istilah tersebut berarti beberapa menit lagi, sementara bagi orang yang tinggal di daerah pedesaan, yang ritme hidupnya tidak sedinamis masyarakat kota, akan memaknai "sebentar" sebagai beberapa jam lagi. Hall juga membedakan pandangan terhadap waktu dan kegiatan. Masyarakat monokromik, melakukan aktivitas mereka satu persatu, sedangkan masyarakat polikromik melakukan beberapa aktivitas pada waktu yang bersamaan.

Konteks juga merupakan faktor yang penting dalam komunikasi. Dalam masyarakat dengan kontekstual tinggi, suatu pesan harus disampaikan secara eksplisit. Hal inilah yang sering menimbulkan kesalah pahaman dalam komunikasi, seseorang dengan latar belakang masyarakat yang memiliki kontekstual rendah, mungkin merasa sudah cukup memberikan 
informasi, tetapi penerima informasi tidak dapat memahami konteks bahasa non verbal yang tersirat.

Pandangan lain yang sering digunakan dalam memahami dimensi budaya universal dalam komunikasi interkultural adalah teori yang diajukan oleh Hofstede. Menurut Hofstede (1997), setiap orang memiliki pola pemikiran, perasaan dan perbuatan yang dipelajari sepanjang hidupnya. Bagaimana seseorang dibesarkan, akan memberikan dampak yang cukup besar terhadap terbentuknya pola tersebut. Kebudayaan seseorang terbentuk karena lingkungan sosial dimana orang tersebut dibesarkan. Hofsted memberikan dimensi budaya yang dapat digunakan untuk mengukur perbedaan antara seseorang dengan latar belakang budaya tertentu dengan budaya yang lain.

Dimensi tersebut yaitu:

1. Power Distance (PD)

2. Individualism vs Collectivism (IDV)

3. Feminity vs Masculinity (MAS)

4. Uncertainty Avoidance (UA)

5. Long Term Orientation (LTO)

Power distance adalah dimensi pengukuran berdasarkan kesetaraan dalam masyarakat. Dalam dimensi ini, orang menerima bahwa kekuasaan tidak terbagi secara merata.

Individualism adalah dimensi masyarakat yang mengutamakan kepentingan dirinya sendiri dan hidup untuk diri sendiri, sebaliknya collectivism merupakan masyarakat yang mengutamakan kehidupan sosial bersama, dimana terkadang kepentingan kelompok lebih diutamakan dibanding kepentingan pribadi.

Masyarakat yang maskulin memiliki budaya yang membedakan peran gender, dimana pria biasanya lebih dominan, dan memiliki sifat-sifat asertif, kompetitif dan tangguh.

Uncertain avoidance merupakan dimensi yang menunjukkan seberapa besar masyarakat dapat menerima ketidakpastian, ketidakjelasan dan sesuatu yang tidak diketahui. Orang dengan latar belakang budaya ini memiliki toleransi yang rendah terhadap sesuatu yang baru yang memiliki resiko yang tidak diketahui.

Orientasi jangka panjang, dijelaskan oleh Hofsted sebagai dimensi yang menunjukkan seberapa besar masyarakat memiliki dedikasi jangka panjang terhadap tradisi mereka atau memiliki pikiran-pikiran yang maju ke depan. 


\section{Desain Antarmuka Berorientasi Budaya}

Dengan memperhatikan dimensi budaya yang telah dikemukakan oleh Hall maupun Hofsted, maka diharapkan pengguna tidak akan mengalami kesulitan dalam memahami desain antarmukayang digunakan, seperti kesalahan komunikasi yang terjadi akibat perbedaan latar belakang budaya.

Dalam penelitiannya, Jhangiani (2006) memberikan contoh yang cukup baik dalam penerapan dimensi budaya Hofstede untuk mengukur antarmuka telepon genggam antara masyarakat India dan Amerika. Beberapa contoh fitur antarmuka yang berhubungan dengan dimensi tersebut:

1. Langkah yang minimal dalam melakukan suatu fungsi, diidentifikasikan sebagai fitur yang berhubungan dengan nilai UA yang tinggi, dimana masyarakat memiliki toleransi yang rendah terhadap ketidakjelasan.

2. Variasi konten (fitur tambahan) diasosiasikan terhadap nilai PD yang rendah. Masyarakat dengan dimensi PD yang tinggi memiliki jarak strata sosial yang jauh dan memilih konten yang terbatas.

3. Pelabelan menu yang jelas diasosiasikan dengan nilai UA yang tinggi

4. Penyajian informasi yang banyak dalam satu layar dalam bentuk ikon maupun menu, merupakan fitur yang menunjukkan berbagai opsi yang tersedia, oleh sebab itu menghindari ambiguitas. Fitur ini berhubungan dengan dimensi UA yang tinggi dan LTO yang rendah. Suatu masyarakat dengan dimensi LTO yang tinggi, menekankan kesabaran, sehingga tidak memerlukan fitur yang menyajikan banyak opsi sekaligus.

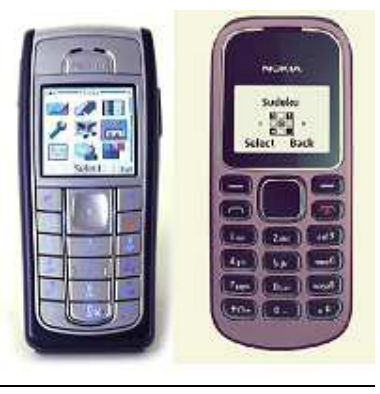

\section{Gambar 5. Penyajian menu}

(http://www.nokia.co.id)

5. Pemanfaatan layar yang efisien tidak cocok diterapkan pada masyarakat dengan dimensi UA yang tinggi. Menampilkan satu menu pada suatu saat, dapat dianggap menimbulkan ketidak jelasan opsi yang tersedia.

6. Personifikasi antarmuka. Fitur ini sangat berkaitan dengan dimensi IDV yang tinggi, dimana pengguna dapat mengubah ring tone, volume, tampilan dan sebagainya. 
7. Penampilan fisik. Fitur yang memperhatikan faktor ergonomis bentuk telepon genggam ini dihubungkan dengan dimensi MAS yang rendah. Hal ini disebabkan budaya feminim yang mengutamakan keindahan dan estetika antarmuka.

\section{Pemetaan Dimensi Budaya Terhadap Perancangan Antarmuka}

Untuk memetakan dimensi budaya ada beberapa tahap yang harus dilalui. Marcus (2000) menjelaskan tahap-tahap itu sebagai berikut: mendefinisikan komponen dari antarmuka pengguna yang ada, menganalisa implikasi dari dimensi budaya terhadap antarmuka pengguna, dan membuat matriks pemetaan elemen antarmuka pengguna terhadap dimensi budaya.

Contoh pemetaan dimensi budaya ke dalam komponen antarmuka telepon genggam, dapat dilihat dalam model penelitian interaksi telepon genggam dengan komponen antarmuka yang telah dilakukan Kim (2005) seperti tampak pada Gambar 6 berikut:

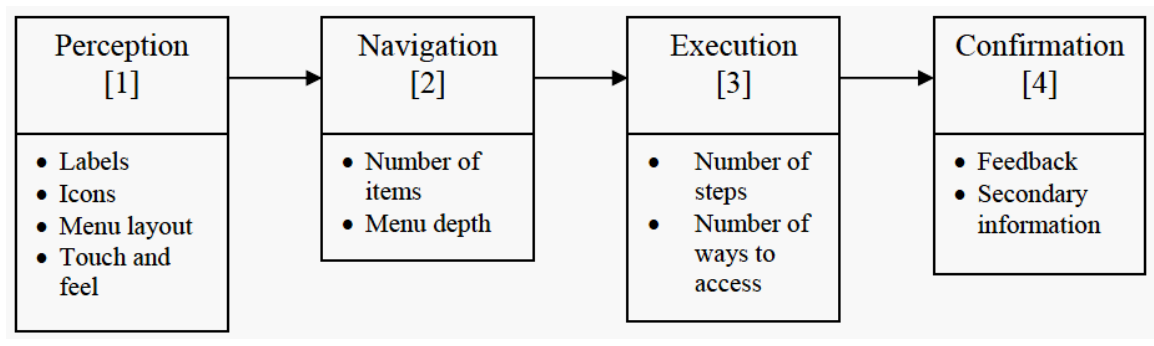

\section{Gambar 6. Model penetilian interaksi telepon genggam dengan komponen antarmuka}

Masing-masing komponen antarmuka tersebut dipetakan terhadap atribut spesifik yang dapat dihubungkan dengan variabel budaya.

Marcus (2000) juga menjelaskan suatu antarmuka memiliki komponen-komponen berikut: metafor, mental model, navigasi, interaksi dan penampilan. Pemetaan yang tepat terhadap komponen-komponen tersebut juga sangat menentukan baik tidaknya suatu antarmuka, seperti contoh yang ditunjukkan oleh Krisnawati dan Restyandito (2008) dimana pengguna tidak memahami makna simbol amplop sebagai ikon untuk mengirimkan pesan (SMS) tetapi memahaminya sebagai media untuk mengirimkan uang (amplop bermanfaat sebagai tempat untuk memberikan hadiah/sumbangan berupa uang). Krisnawati dan Restyandito, menunjukkan bahwa penggunaan metafor meja kerja, tidak sepenuhnya 
tepat jika diterapkan pada pengguna dengan latar belakang petani atau pedagan pasar yang tidak pernah bekerja di belakang meja.

\section{Kesimpulan}

Perkembangan teknologi yang begitu cepat dan penetrasi wilayah yang demikian luas tidak menjamin bahwa pengguna teknologi tersebut dapat dengan mudah beradaptasi dalam memahami antarmuka yang ada. Seperti yang telah ditunjukkan oleh Krisnawati dan Restyandito (2006). Hal ini disebabkan pemahaman yang berbeda karena latar belakang budaya pengguna yang beragam.

Salah satu kunci keberhasilan perancangan antarmuka yang baik, adalah dengan memahami dan mempertimbangkan dimensi budaya seperti yang telah dikemukakan oleh Hall dan Hofstede.

\section{Daftar Pustaka}

Barber, W., Badre, A. (1998, June). Culturability: The Merging of Culture and Usability, 4th Conference on Human Factors \& the Web, New Jersey

Gould, E.W. (2005). Synthesizing the Literature on Cultural Values, dalam N.Aykin (Ed), Usability and

Internationalization of Information Technology, Mahwah, New Jersy, Laurence Erlbaum Associates.

Hall, E.T. (1973). The Silent Language, Anchor

Hall, E.T. (1976). Beyond Culture, New York: Doubleday

Hofstede, G. (1997). Cultures and Organizations: Software of the Mind. McGraw-Hill

Jhangiani, I. (2006). A Cross-Cultural Comparison of Cellphone Interface Design Preferences from the Perspective of National and Disability. Virginia Polytechnic Institute and State University

Kim, S., Kim, J.M., Choo, H., Kim, (2003, June). Cultural Issues in Handheld Usability - Are Cultural Models Effective for Interpreting Unique Use Patters of Korean Mobile Phone?, Usability Professionals' Association Conference, Scottsdale, Arizona.

Krisnawati, L.D., Restyandito (2006, December). Factors Inducing Cellphone User's Competency: An Empirical Study, The First International Workshop on Mobile Multimedia Information Retrieval, MoMIR 2006

Krisnawati, L.D., Restyandito (2008, January-March). Localized User Interface for Improving Cellphone Users Device Competency, International Journal of Information Technology and Web Engineering, Vol.3, No.4, IGI Publishing

Marcus, A. \& Gould, F.W (2000), Crosscurrents Cultural Dimensions and Global Web User-Interface Design Interaction 